\title{
Study on Evolution of China's Construction Industry Based on Input-Output Analysis and Complex Network
}

\author{
Xianrui MA, Chunlei HUANG, Yan FU, Jingxin GAO, Beibei QIN
}

\begin{abstract}
Exploring the evolution of China's construction industry is conducive to the formulation of industrial policies. The construction industry is associated with many industries. Hence, the policies formed according to internal evolution of the construction industry are easy to direct the industry toward an unfavourable direction. This study aims to analyze the evolution of construction industry based on the relationships between the construction industry and other industries. The pull coefficients and push coefficients of China's construction industry during 2001-2015 were calculated based on the input-output table. Complex network topologies of industries were constructed, and network topologies were used to analyze the network centrality and the cohesive subgroups. The evolutionary trend of China's construction industry in interactions with other industries was explored. Results show that the pull and push effects of China's construction industry experience a sharp reduction. The construction industry has the inclination to be transformed from a pillar industry to an industry driven by other industries. The control of the construction industry in the network is weakened. In conclusion, using input-out analysis and complex network to study the evolution of China's construction industry can consider interaction of different industries, and provide certain theoretical references to formulate reasonable policies.
\end{abstract}

Keywords: complex network; construction industry; evolution; industrial association; input-output analysis

\section{INTRODUCTION}

The construction industry plays an important role in the development of countries around the whole world. China's construction industry has made remarkable contributions to economic growth and urbanization process in the country [1]. China's construction industry is one of the pillars of the national economy; although China's construction industry has grown in four decades since the reform and opening-up policy, it is still facing problems of low benefits and low efficiency. China's construction industry is in an extensive development stage compared with other industries, such as manufacturing [2]. Therefore, a new development mode has to be explored in order to change the current extensive development and improve the industrial production level and innovation ability of enterprises [3]. Development of the construction industry is a complicated and dynamic process, and it is highly sensitive to any industrial changes [4]. With comprehensive consideration of the interaction of different industries, the evolution of China's construction industry is studied. Such research is beneficial to comprehend the overall development trend, formulate industrial policies in accordance with the law of development, and promote transition and sustainable growth of the construction industry.

Existing studies on evolution of the construction industry mainly focus on the evolution of the relationship between the construction industry development and the overall national economy [5]. However, the relationship between the construction industry and different industries contributing to the national economy has been rarely discussed. Studies on influencing factors of evolution of the construction industry are used to recognize influencing factors from the internal structure (e.g., technology, organization, and market) and analyze the action mechanisms of these influencing factors [6]. However, influences of other industries are neglected. Studies on the evolutionary trend of the construction industry and countermeasures mainly focus on the internal structural evolution of construction industry and provide corresponding development strategies [7]. Studies on the mutual evolutionary relationship between the construction industry and other industries are lacking. In general, studies of the evolution of the construction industry often neglect the mutual influences between the construction industry and other industries. Instead, they determine the internal evolution of the construction industry, as well as the corresponding countermeasures [8], which may be against the formulation of adaptive development policies for the construction industry. Analyzing the evolution of China's construction industry in direct and indirect association with other industries and determining the evolutionary trend of the construction industry in middle and long periods have important theoretical value and practical significance in promoting sustainable development of the construction industry.

\section{STATE OF THE ART}

Existing studies on evolution of the construction industry mainly focus on its relationship with the national economy. Based on Engineering New-Record's investigation data of 150 countries, Crosthwaite [9] carried out a regression analysis on the relationship between the share of construction spending in GDP and per capita GDP. An inverted U-shaped relationship was found between them. Choi et al. [10] implemented the horizontal and vertical analysis on the time series data of the construction industry and national economy in Korea, thereby demonstrating the existence of the inverted U-shaped curve. Based on input-output analysis, Ick [11] pointed out that the construction industry of Korea promoted the national economic growth by forming infrastructure, housing, and other fixed assets. Liu et al. [12] applied the forward and backward linkage indicators, which were concluded from the input-output analysis, to study the contributions of Australia's construction industry to the gross national product (GNP) and gross national income (GNI). The existence of a relationship between the evolution of construction industry and the national economy is widely accepted. However, such studies only 
focus on the relationship between construction industry and the overall economic development. The association between China's construction industry and other industries of the national economy has hardly been discussed.

Some studies have attempted to explore the factors that influence the construction industry's evolution. Based on the geographically weighted regression model, Chen et al. [13] demonstrated that economic environment, industrial organization structure, and technological level could influence the evolution of construction industry around China significantly. Mao et al. [14] recognized influencing factors of evolution of the construction industry in China through a questionnaire investigation and factor analysis, which were classified into government regulations and policies, technological innovation, industry supply chain, cost, and market demand. Arditi et al. [15] performed a questionnaire survey on 400 contractors in America and concluded that cost control, scheduling, design review, labour training, and quality control were potential factors affecting the sustainable development of construction industry in America. Ofori [16] stated that process integration, service export, business networks, and procurement arrangements were important factors affecting the growth of the construction industry in Singapore. These influencing factors of the construction industry evolution and their effects vary in different countries. Existing studies mainly discuss internal influencing factors of the construction industry, but influences of other industries on the construction industry are hardly studied.

The evolutionary trend and development strategies of the construction industry are mainly studied from the perspective of industrial structure. An empirical study on the construction industry in America analyzed the industrial structure and development strategy from the perspectives of size, growth rate, business stability, and market diversification [17]. By considering capital requirements, product differentiation, legal barriers, scale of economies, and exit barriers, Zeng et al. [18] discussed the evolution of the low-concentration structure of China's construction industry by using the Lorenz curve and Gini coefficient. Meanwhile, some recommendations, such as raising entry barriers and lowering exit barriers, were proposed. Based on the structure-behaviour-performance paradigm and the multivariate regression analysis, Liu et al. [19] discovered that market structure influenced the construction industry more than the ownership structure. They suggested the increase in the concentration ratio of industry and the promotion of privatization reform. According to statistical data analysis of the construction industry in China, Li et al. [20] concluded that there were many large-scale construction enterprises, and these were accompanied by unreasonable proportions of comprehensive enterprises and professional enterprises. Liu et al. [21] analyzed interaction mechanisms of scale structure, ownership structure, industry structure, and professional structure of the construction industry among the western, central, and eastern regions in China; their results provided an evolution direction of construction industry in different regions. Many studies focus on structural problems in the construction industry and attempt to explore the corresponding evolution route from the industrial structure. Nevertheless, the associations of the construction industry with other industries and its influences on industrial structure have been hardly discussed.

Existing studies on evolution of the construction industry lay a good theoretical foundation for the sustainable growth of China's construction industry and the industrial restructuring. However, many studies emphasize the internal evolution of the construction industry. On the contrary, the dynamic associations between the construction industry and other industries are rarely involved when discussing the construction industry's relationship with the national economy, as well as the influencing factors of evolution or industrial structure issues. Thus, based on the Eora inputoutput table, the total consumption coefficients, total distribution coefficients, pull coefficients, and push coefficients of the construction industry to other industries were calculated using the investigation data of 123 industrial sectors in China during 2001-2015 in this study. Moreover, complex industrial networks were constructed based on the total coefficients matrix. Changes in the relationship between China's construction industry and other industries in 15 years were analyzed through network centrality and cohesive subgroups. The evolutionary trend of the construction industry in association with other industries was discussed. This study offsets the existing poor coverage of industrial sectors in studies on evolution of China's construction industry.

The remainder of this study is organized as follows. Section 3 introduces the calculation methods of total consumption coefficients, pull coefficients, total distribution coefficients, and push coefficients of the construction industry. Moreover, the construction criteria and methods of complex industrial networks based on the total coefficient matrix and the principles of centrality analysis and cohesive subgroup analysis are described. Section 4 calculates the total consumption coefficients, total distribution coefficients, pull coefficients, and push coefficients of China's construction industry in 15 years. Network centrality and cohesive subgroups are analyzed. The relationship between China's construction industry and other industries, as well as its evolutionary trend, is discussed. Section 5 summarizes the conclusions.

\section{METHODOLOGY}

\subsection{Total Consumption Coefficient and Pull Coefficient}

In input-output analysis, the total consumption coefficient refers to the total consumption quantity of other products for the unit output of a product [22]

$$
\boldsymbol{B}=\boldsymbol{A}+\boldsymbol{C}
$$

where $\boldsymbol{A}$ is the direct consumption coefficient matrix, $\boldsymbol{C}$ is the indirect consumption coefficient matrix, and $\boldsymbol{B}$ is the total consumption coefficient matrix.

$$
\begin{aligned}
& \boldsymbol{A}=\left[a_{i j}\right]_{n \times n} \\
& \boldsymbol{C}=\boldsymbol{B} \cdot \boldsymbol{A}
\end{aligned}
$$

where $a_{i j}$ is the direct consumption of product $i$ for the unit output of sector $j$ in the input-output table. The following can be known from Eq. (1) and Eq. (3): 


$$
\boldsymbol{B}=(\boldsymbol{I}-\boldsymbol{A})^{-1}-\boldsymbol{I}
$$

$\boldsymbol{I}$ is the unit matrix of same order. The total consumption coefficients of different sectors are calculated from Eq. (4), which disclose the direct and indirect relationships of different sectors from the perspective of product consumption. In this study, the total consumption coefficient is employed to recognize industries on which the construction industry has a significant pull effect. The total consumption coefficient is also the basis for the calculation of the pull coefficient.

The pull coefficient $\left(F_{j}\right)$ is equal to the ratio of the column sum of total consumption coefficients divided by the number of sectors $(n)$ to the sum of all total consumption coefficients divided by the square of the number of sectors $\left(n^{2}\right)[23,24]$ :

$$
F_{j}=\frac{\frac{1}{n} \sum_{i=1}^{n} b_{i j}}{\frac{1}{n^{2}} \sum \sum b_{i j}}=\frac{\sum_{i=1}^{n} b_{i j}}{\frac{1}{n} \sum \sum b_{i j}}(j=1,2, \ldots, n)
$$

where $b_{i j}$ is the total consumption coefficient of sector $j$ to the sector $i . F_{j}$ is the sum of increment of gross output in all sectors brought by the unit final product of sector $j$. The higher value of $F_{j}$ reflects the stronger pull effect of the sector $j$ on other sectors. In this study, the pull coefficient is used to analyze the pull effect of the construction industry on other industries.

\subsection{Total Distribution Coefficient and Push Coefficient}

A complete analysis system that is symmetrical with the consumption coefficient can be established based on the distribution coefficient. The calculation method of the total distribution coefficient is similar to the total consumption coefficient, except that the vertical calculation is changed into the horizontal calculation [25].

$$
\boldsymbol{R}=\left[r_{i j}\right]_{n \times n}
$$

$\boldsymbol{R}$ is the direct distribution coefficient matrix, and $r_{i j}$ is the proportion of the intermediate consumption quantity of the product of the sector $i$ which is distributed to the sector $j$ in the total yield. The distribution coefficient is symmetrical with the consumption coefficient. According to the symmetric structure, the following is obtained:

$$
\boldsymbol{D}=(\boldsymbol{I}-\boldsymbol{R})^{-1}-\boldsymbol{I}
$$

$\boldsymbol{I}$ is the unit matrix of same order and $\boldsymbol{D}$ is the total distribution coefficient matrix. The total distribution coefficients of sectors can be gained from Eq. (7). The direct and indirect relationships of sectors are disclosed from the perspective of distribution of investment values. In this study, the industries on which the construction industry has a significant push effect are recognized by the total distribution coefficient. The total distribution coefficient is also the basis for calculating the push coefficient.
The push coefficient $\left(F_{i}\right)$ is equal to the ratio of the row sum of total distribution coefficients divided by the number of sectors $(n)$ to the sum of all total distribution coefficients divided by square of the number of sectors $\left(n^{2}\right)[26]$ :

$$
F_{i}=\frac{\frac{1}{n} \sum_{j=1}^{n} d_{i j}}{\frac{1}{n^{2}} \sum \sum d_{i j}}=\frac{\sum_{j=1}^{n} d_{i j}}{\frac{1}{n} \sum \sum d_{i j}}(j=1,2, \ldots, n)
$$

where $d_{i j}$ is the total distribution coefficient of sector $i$ to the sector $j . F_{i}$ refers to the output increase of all sectors which are contributed to the initial unit input of the sector $i$. The higher value of $F_{i}$ reflects the stronger push effect of sector $i$ on other sectors. In this study, the push coefficient is applied to analyze the push effect of the construction industry on other industries.

\subsection{Construction and Measurement of Complex Networks}

Complex networks of China's industries were constructed based on the total distribution coefficients and total consumption coefficients. The total coefficient matrix should be converted into 0-1 matrix first. Selection of threshold is the premise of conversion. Generally, the matrix mean is often chosen as the threshold. The converted coefficient is 1 if the original coefficient is higher than the threshold, thereby indicating the associations among different sectors. Otherwise, the converted coefficient is 0 , thereby indicating that association among the sectors is absent [27].

The complex networks of China's industries were constructed using the Ucinet software through the matrix after conversion. The network topologies were drawn by Netdraw. In the present study, the current industrial networks were measured by the centrality analysis and cohesive subgroup analysis to discuss the role of construction industry in industrial networks.

Centrality reflects the importance of an industry in the network. It includes point and betweenness centralities [28]. The point centrality emphasizes the measurement of number of direct connections between one point and other points, as follows:

$C_{D}\left(N_{i}\right)=\sum_{j=1}^{g} x_{i j}(i \neq j)$

where $C_{D}\left(N_{i}\right)$ is the point centrality of point $i$ and $\sum_{j=1}^{g} x_{i j}(i \neq j)$ is to calculate the number of connections between point $i$ and other point $j$. Point centrality includes out-degree and in-degree, which express the number of sides from one sector in the network and the number of sides to the sector. Here, out-degree and in-degree represent the number of industries associated with the construction industry.

The betweenness centrality is used to measure the control degree of one point over resources, as follows: 


$$
C_{B}\left(N_{i}\right)=\sum_{j<k} \frac{g_{j k}\left(N_{i}\right)}{g_{j k}}
$$

where $C_{B}\left(N_{i}\right)$ is the betweenness centrality of point $i . g_{j k}$ is the number of the shortest paths between points $j$ and $k$. $g_{j k}\left(N_{i}\right)$ is the number of the shortest paths between the points $j$ and $k$ that all pass through the point $i$. Betweenness centrality measures the association degree of one point and two adjacent points. In this study, betweenness centrality describes the dependence of other industries associated with the construction industry on the construction industry.

Cohesive subgroup analysis is used to study the actual or potential relationships among different social actors [29]. Cohesive subgroup is a subset of actors with relatively close relationships, whereas the relationship among different subsets is further than the relationships of actors in the same subset. In this study, a cohesive subgroup analysis is used to measure the relationship between the construction industry and other industries in the network.

\section{RESULT ANALYSIS AND DISCUSSION 4.1 Data Source}

The total consumption coefficients and total distribution coefficients of different industries in China were calculated using the Eora input-output table. Since the 1970s, the Eora database has provided the input-output tables of major countries in the world that have relatively detailed departmentation. The input-output table of China covers 123 industrial sectors (names and codes of sectors are listed in www.worldmrio.com) [30]. Data statistics in the Eora input-output table has to consume much time, and data are updated slowly. The latest data of this table use the data in 2015. Therefore, the basic price input-output table from 2001 to 2015 was applied to the analysis of the evolution of the relationship between the construction industry and other industries.

\subsection{Input-output Analysis of the Construction Industry}

The evolutionary trend of China's construction industry and its pull effect and push effect on other industries were analyzed from the perspectives of input and output based on the calculation methods of total consumption coefficient, total distribution coefficient, pull coefficient, and push coefficient in Sections 3.1 and 3.2.

\subsubsection{Total Consumption Coefficients and Pull Coefficients}

Total consumption coefficient represents the consumption quantity of other sectors' products per unit output of the construction industry. Total consumption coefficients of China's construction industry to other 122 industries from 2001 to 2015 were calculated (Tab. 1). Limited by the volume of the article, only codes of the first 20 industries with the highest total consumption coefficients are listed (codes and their corresponding names can be queried on worldmrio.com/countrywise/).

Table 1 Codes of first 20 industries with the highest total consumption coefficients of the construction industry

\begin{tabular}{|c|c|c|c|c|c|c|c|c|c|c|c|c|c|c|c|}
\hline Ranking & 2015 & 2014 & 2013 & 2012 & 2011 & 2010 & 2009 & 2008 & 2007 & 2006 & 2005 & 2004 & 2003 & 2002 & 2001 \\
\hline 1 & 7 & 7 & 86 & 86 & 86 & 86 & 86 & 86 & 86 & 7 & 7 & 36 & 36 & 36 & 36 \\
\hline 2 & 86 & 86 & 36 & 36 & 36 & 36 & 36 & 36 & 36 & 36 & 36 & 7 & 7 & 7 & 7 \\
\hline 3 & 36 & 36 & 7 & 7 & 7 & 7 & 7 & 7 & 7 & 86 & 86 & 101 & 101 & 101 & 101 \\
\hline 4 & 85 & 85 & 85 & 85 & 85 & 85 & 85 & 85 & 85 & 85 & 101 & 85 & 85 & 85 & 86 \\
\hline 5 & 8 & 8 & 101 & 101 & 101 & 101 & 101 & 101 & 101 & 101 & 85 & 86 & 86 & 86 & 85 \\
\hline 6 & 84 & 84 & 84 & 84 & 84 & 84 & 84 & 84 & 84 & 93 & 93 & 8 & 8 & 8 & 8 \\
\hline 7 & 63 & 63 & 93 & 93 & 93 & 93 & 93 & 93 & 93 & 1 & 8 & 93 & 93 & 93 & 1 \\
\hline 8 & 56 & 32 & 63 & 63 & 63 & 63 & 63 & 63 & 56 & 8 & 63 & 1 & 1 & 63 & 93 \\
\hline 9 & 9 & 56 & 56 & 56 & 56 & 56 & 56 & 56 & 63 & 63 & 32 & 32 & 63 & 32 & 63 \\
\hline 10 & 32 & 1 & 8 & 32 & 32 & 32 & 32 & 32 & 32 & 32 & 1 & 63 & 32 & 1 & 32 \\
\hline 11 & 103 & 9 & 32 & 8 & 8 & 8 & 8 & 8 & 8 & 91 & 91 & 103 & 103 & 103 & 48 \\
\hline 12 & 115 & 60 & 1 & 60 & 60 & 1 & 60 & 1 & 60 & 103 & 56 & 48 & 48 & 48 & 103 \\
\hline 13 & 60 & 103 & 60 & 1 & 1 & 60 & 1 & 103 & 103 & 56 & 103 & 91 & 91 & 91 & 115 \\
\hline 14 & 48 & 48 & 103 & 103 & 103 & 103 & 103 & 60 & 1 & 99 & 99 & 115 & 115 & 115 & 56 \\
\hline 15 & 104 & 115 & 91 & 91 & 91 & 91 & 91 & 91 & 91 & 104 & 90 & 56 & 56 & 56 & 91 \\
\hline 16 & 1 & 104 & 104 & 104 & 104 & 104 & 104 & 104 & 104 & 48 & 104 & 104 & 60 & 60 & 60 \\
\hline 17 & 99 & 23 & 115 & 115 & 115 & 115 & 115 & 115 & 115 & 60 & 48 & 60 & 104 & 104 & 99 \\
\hline 18 & 23 & 99 & 48 & 48 & 48 & 48 & 48 & 48 & 48 & 115 & 60 & 99 & 99 & 99 & 104 \\
\hline 19 & 108 & 108 & 108 & 108 & 108 & 108 & 108 & 99 & 108 & 90 & 115 & 90 & 90 & 90 & 90 \\
\hline 20 & 12 & 46 & 99 & 99 & 99 & 23 & 23 & 108 & 99 & 108 & 108 & 4 & 4 & 4 & 4 \\
\hline
\end{tabular}

The total consumption coefficients of the construction industry to the petroleum refining industry and coal mining and processing industry occupied the first three positions from 2001 to 2015. The total consumption coefficient of the construction industry to the gas production and supply industry was in the first five positions before 2004, and its ranking has since been increasing, thereby occupying the first two positions from 2007 to 2015. From 2001 to 2015, the total consumption coefficients of the construction industry to steel processing, electricity and steam production, and crude petroleum products were in the first 20 positions although they fluctuated to different extents. The construction industry has a significant pull effect on the above-mentioned industries, and products of these industries are the major production elements of the construction industry. In addition, the pull effect of the construction industry on the finance industry has been increasing steadily for 15 years, indicating the increasing importance of capitals in the construction industry. Although the pull effects of the construction industry on the above-mentioned industries are changing continuously, these industries are in the top rank for total consumption coefficient. This finding reflects that the construction industry does not induce substantial changes in the consumption structure of products of other industries. 
The pull coefficients of the construction industry to other industries during 2001-2015 were calculated by the total consumption coefficients (Fig. 1).

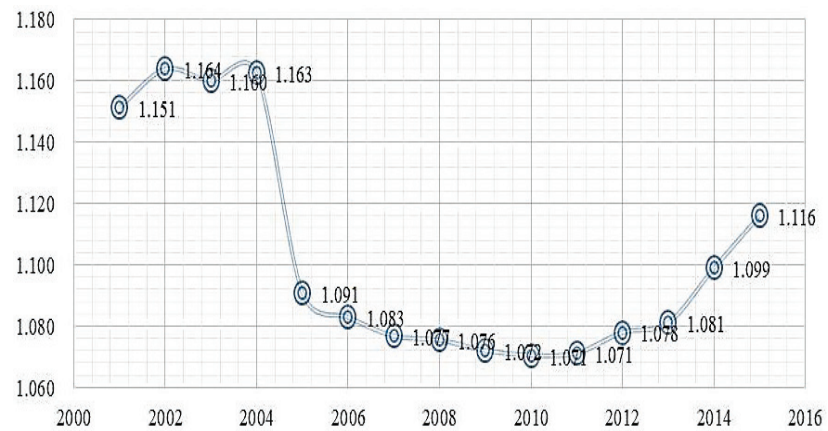

Figure 1 Pull coefficients of China's construction industry during 2001-2015

The pull coefficient of China's construction industry fluctuated between 1.15 and 1.165 from 2001 to 2004, and this coefficient was kept at a high level. However, it decreased continuously after 2004 and increased gradually after 2011. It increased to 1.116 in 2015, and this level still differed from that obtained in 2004.

\subsubsection{Total Distribution Coefficients and Push Coefficients}

Total distribution coefficient reflects the quantity of unit initial investment, which is distributed by the construction industry to different industries. The total distribution coefficients of China's construction industry to other 122 industries during 2001-2015 were calculated (Tab. 2). Limited by the volume of the article, only codes of the first 20 industries with the highest total distribution coefficients are listed (codes and their corresponding names can be queried on worldmrio.com/countrywise/).

Although the total distribution coefficients of the first 20 industries fluctuated during 2001-2015, the industrial structure remained the same. Educational services ranked first (except 2012) in terms of total distribution coefficient. In addition, the construction industry also distributed great unit initial investments to real estate, public administration, wholesale and retail trade, finance, resident services, health services, steel-processing, and railway freight transport. These industries are major consumers of the construction products and have great demand for construction products. The construction industry has a significant push effect on these industries, thereby conforming to the current situation in China. These industries are in the top rank with respect to total distribution coefficient, although the push effects of construction industry are changing continuously, thereby indicating that no substantial changes have occurred to the distribution structure of construction products to these industries.

Table 2 Codes of first 20 industries with the highest total distribution coefficients of the construction industry

\begin{tabular}{|c|c|c|c|c|c|c|c|c|c|c|c|c|c|c|c|}
\hline Ranking & 2015 & 2014 & 2013 & 2012 & 2011 & 2010 & 2009 & 2008 & 2007 & 2006 & 2005 & 2004 & 2003 & 2002 & 2001 \\
\hline 1 & 116 & 116 & 116 & 88 & 116 & 116 & 116 & 116 & 116 & 116 & 116 & 116 & 116 & 116 & 116 \\
\hline 2 & 88 & 88 & 88 & 116 & 88 & 88 & 88 & 88 & 88 & 106 & 106 & 106 & 106 & 106 & 106 \\
\hline 3 & 122 & 122 & 122 & 85 & 106 & 106 & 106 & 106 & 106 & 122 & 122 & 122 & 122 & 122 & 122 \\
\hline 4 & 106 & 85 & 106 & 56 & 122 & 122 & 122 & 122 & 122 & 88 & 88 & 101 & 101 & 101 & 101 \\
\hline 5 & 85 & 106 & 117 & 122 & 101 & 101 & 101 & 101 & 101 & 101 & 101 & 88 & 88 & 88 & 88 \\
\hline 6 & 101 & 56 & 101 & 106 & 117 & 117 & 117 & 117 & 117 & 104 & 104 & 104 & 104 & 104 & 115 \\
\hline 7 & 117 & 101 & 104 & 101 & 85 & 85 & 85 & 85 & 85 & 115 & 115 & 115 & 115 & 115 & 1 \\
\hline 8 & 56 & 117 & 85 & 117 & 104 & 104 & 104 & 104 & 104 & 85 & 1 & 1 & 1 & 1 & 104 \\
\hline 9 & 104 & 104 & 115 & 104 & 115 & 115 & 115 & 115 & 115 & 1 & 117 & 102 & 117 & 117 & 117 \\
\hline 10 & 115 & 115 & 56 & 93 & 56 & 56 & 56 & 56 & 56 & 90 & 85 & 117 & 102 & 102 & 102 \\
\hline 11 & 1 & 60 & 90 & 60 & 90 & 90 & 90 & 90 & 90 & 117 & 102 & 90 & 90 & 90 & 85 \\
\hline 12 & 90 & 1 & 111 & 115 & 102 & 102 & 102 & 74 & 74 & 102 & 90 & 85 & 85 & 85 & 90 \\
\hline 13 & 60 & 63 & 102 & 63 & 111 & 111 & 111 & 102 & 102 & 99 & 99 & 111 & 111 & 111 & 99 \\
\hline 14 & 111 & 93 & 1 & 36 & 1 & 1 & 1 & 111 & 111 & 74 & 111 & 99 & 99 & 99 & 111 \\
\hline 15 & 63 & 36 & 74 & 1 & 74 & 74 & 74 & 1 & 1 & 108 & 108 & 103 & 103 & 103 & 103 \\
\hline 16 & 102 & 74 & 60 & 74 & 60 & 60 & 60 & 60 & 60 & 56 & 74 & 56 & 56 & 56 & 4 \\
\hline 17 & 74 & 90 & 63 & 73 & 63 & 63 & 63 & 108 & 108 & 111 & 56 & 4 & 4 & 4 & 56 \\
\hline 18 & 65 & 111 & 108 & 65 & 108 & 108 & 108 & 63 & 73 & 73 & 89 & 60 & 89 & 89 & 23 \\
\hline 19 & 36 & 65 & 99 & 91 & 36 & 36 & 36 & 73 & 63 & 89 & 103 & 89 & 60 & 36 & 36 \\
\hline 20 & 73 & 73 & 36 & 90 & 73 & 73 & 73 & 36 & 36 & 60 & 73 & 36 & 36 & 60 & 74 \\
\hline
\end{tabular}

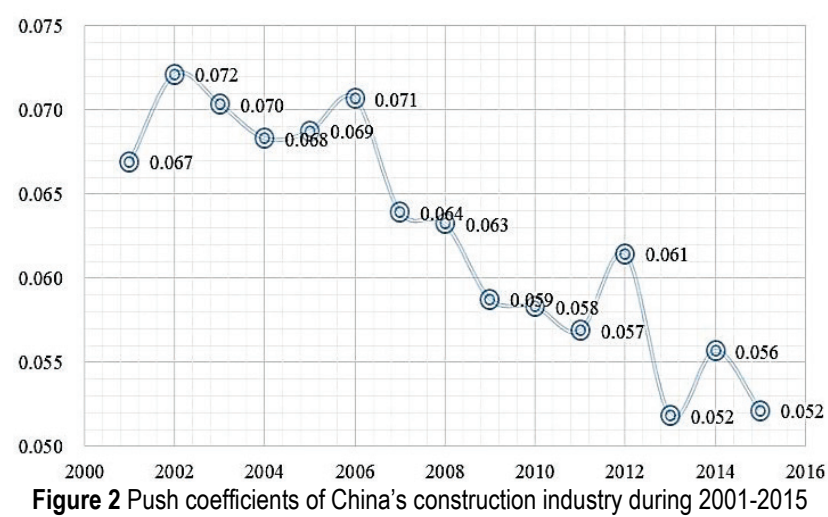

Figure 2 Push coefficients of China's construction industry during 2001-2015
The push coefficients of the construction industry to other industries during 2001-2015 were calculated by the total distribution coefficients (Fig. 2).

Fig. 2 shows that the push effect of China's construction industry decreased continuously. The push coefficient was relatively stable $(0.065-0.075)$ from 2001 to 2006, but it began to decrease after 2006. Although it increased slightly in 2012, it decreased sharply in 2013. The push coefficient was 0.052 in 2015 , which was $27.8 \%$ lower than in 2002.

The pull coefficient and push coefficient of China's construction industry increased first and then decreased dramatically during 2001-2015. The pull coefficient increased after 2012 due to the favourable effects of the rapid development of real estate market, but it was still 
greatly different from that in 2004. The reason for the sharp reduction of pull and push coefficients might be the great impact of emerging industries on traditional industries such as construction industry since 2006 when China's reform was strengthened. Although the construction industry is an important engine of China's GDP growth, the construction industry has not formed a close relationship with other industries in recent years, thereby failing to reach the strongest driving force to other industries.

\subsection{Analysis of China's Construction Industry Based on the Complex Network}

Complex networks of industries in China were constructed and the current association networks of the construction industry were measured based on the calculation criteria of network threshold, centrality analysis, and cohesive subgroup analysis in Section 3.3. The evolutionary trend of the construction industry and its relationships with different industries were discussed from the time series.

Table 3 The pull network thresholds and push network thresholds during 20012015

\begin{tabular}{|c|c|c|}
\hline Years & Pull network thresholds & Push network thresholds \\
\hline 2015 & 0.013119 & 0.018294 \\
\hline 2014 & 0.014488 & 0.021713 \\
\hline 2013 & 0.015559 & 0.019155 \\
\hline 2012 & 0.015802 & 0.025261 \\
\hline 2011 & 0.016372 & 0.020231 \\
\hline 2010 & 0.016422 & 0.020453 \\
\hline 2009 & 0.016311 & 0.020453 \\
\hline 2008 & 0.015898 & 0.020886 \\
\hline 2007 & 0.015933 & 0.020783 \\
\hline 2006 & 0.014219 & 0.018032 \\
\hline 2005 & 0.014369 & 0.017184 \\
\hline 2004 & 0.012136 & 0.015191 \\
\hline 2003 & 0.012325 & 0.015144 \\
\hline 2002 & 0.012178 & 0.015095 \\
\hline 2001 & 0.012419 & 0.01531 \\
\hline
\end{tabular}

\subsubsection{Construction of Complex Networks of Industries in China}

The network thresholds during 2001-2015 were calculated according to the calculation criterion in Section 3.3 (Tab. 3).

The complex network involving 123 industries in China was constructed by using the Ucinet software through the 0-1 matrix. The pull and push network topologies during 2001-2015 were drawn by Netdraw (Fig.3). Only the push network topology in 2015 was provided.

\subsubsection{Centrality Analysis}

The point centrality and betweenness centrality of the network topology in Fig. 3 were calculated by Ucinet software to analyze the network characteristics of China's construction industry.

(1) Point centrality

The calculated results of the out-degree and in-degree of the pull and push networks of China's construction industry are shown in Figs. 4 and 5.

In Fig. 4, the out-degree of the pull network of the construction industry increased continuously since 2001 and reached the peak (49) in 2006. Subsequently, it began to decrease and reached 0 in 2013. However, it increased to 17 in 2014 and 2015. The in-degree was kept at 33-34 during 2001-2012, but it increased dramatically in 2013 and recovered to 37-41 after 2014. The variation rule of the out-degree of the pull network is similar to that of the pull coefficient, thereby confirming the weakening pull effect of the construction industry on other industries. The in-degree exceeded the out-degree after 2006 and became significantly higher than the out-degree since 2013. This reflects that more industries have begun to drive the development of the construction industry since 2013, and the construction industry has the inclination to transform from a pillar industry to an industry driven by other industries. Such transition is related to the proposal of a new national urbanization strategy, continuous warming of the real estate market, and development of emerging industries.

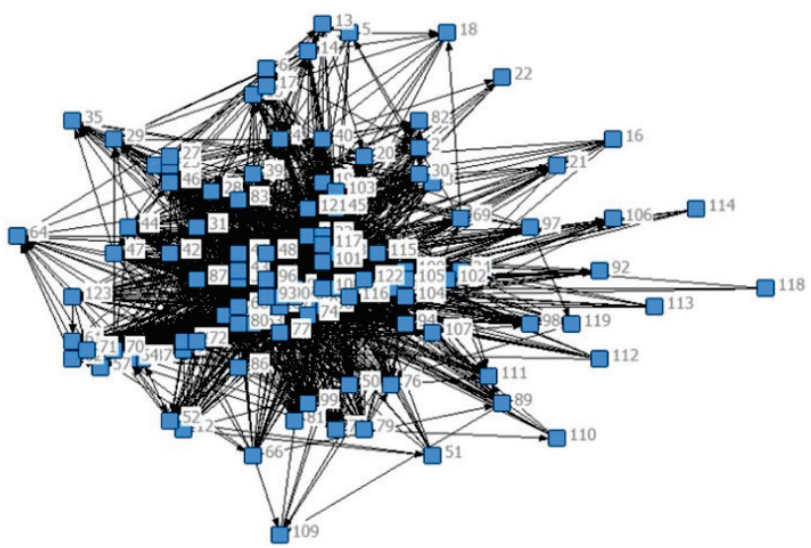

Figure 3 Push network topology of China's industries in 2015

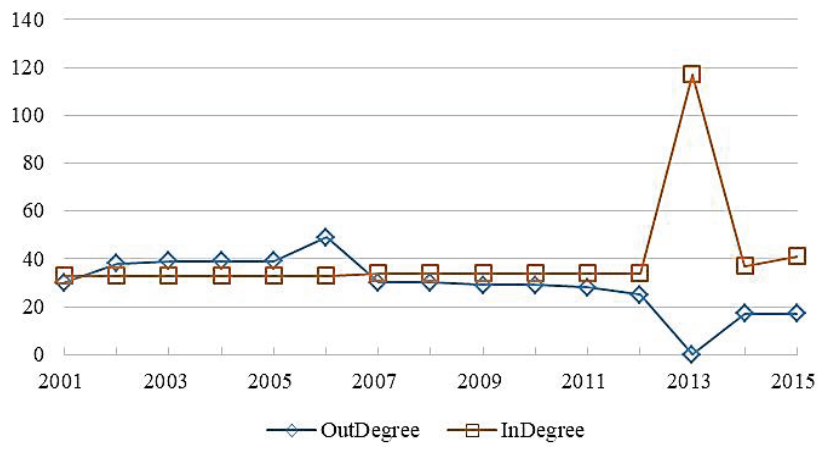

Figure 4 Point centrality of the pull network of China's construction industry during 2001-2015

In Fig. 5, the point centrality of the push network is inconsistent with that of the pull network. In the push network, the out-degree was 0 during 2001-2015. The indegree was kept stable (114-119) except for the significant $\mathrm{V}$-shaped variation in 2004 and 2013. The out-degree of the construction industry in the push network remained 0 , which was related to the threshold used in the construction of 0-1 matrix. Since the mean of total distribution coefficients or total consumption coefficients is chosen as the threshold, the 0 out-degree implies that the push effect of the construction industry on other industries is weaker than the average level of push effect between industries. In the push network, the in-degree is significantly higher than the out-degree, thereby indicating that the push effect of other industries on the construction industry is stronger 
than the push effect of the construction industry on other industries. The sharp reduction of in-degree in 2004 and 2013 might be due to the excessive production factors affecting the construction industry with rapid economic development. However, the output was low, thereby weakening the push effect of other industries on the construction industry.

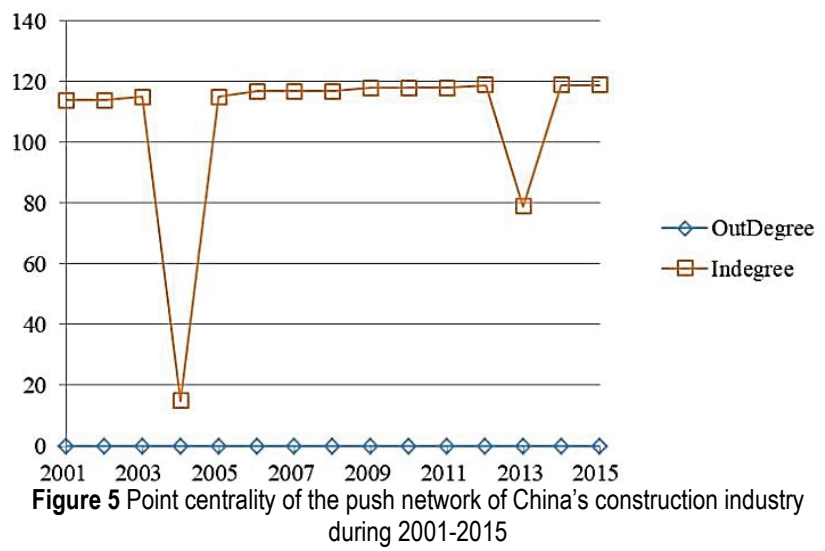

(2) Betweenness centrality

Betweenness centrality reflects the control of the construction industry on the industrial network. In this study, the betweenness centrality of China's construction industry and its variation trend during 2001-2015 are shown in Fig. 6.

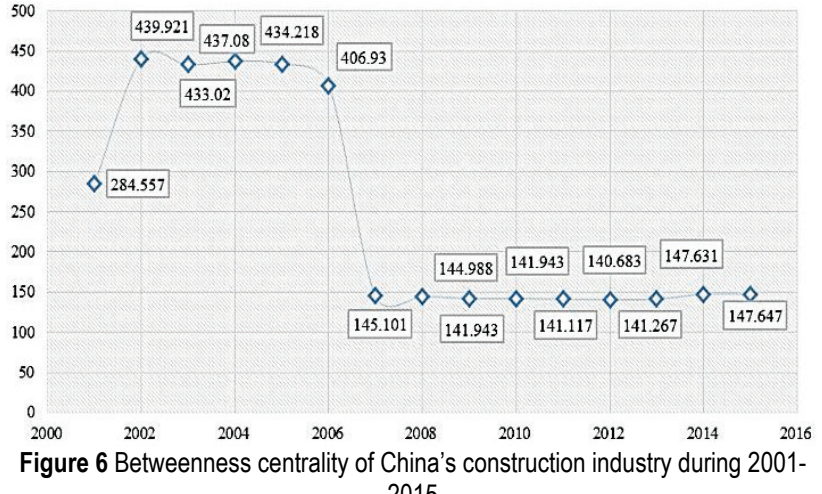

2015

The betweenness centrality increased continuously from 2001 to 2002, but it remained stable from 2002 to 2006 at higher than 400. However, the betweenness centrality declined sharply in 2007 and remained at 140150 from 2007 to 2015. According to changes of betweenness centrality in 15 years, the control of the construction industry in the industrial network increased and decreased significantly and finally remained at a low level, thereby showing a certain similarity with the changes of pull and push coefficients. In particular, the betweenness centrality dropped significantly after 2006, thereby indicating the remarkable weakening of control and the hub position of the construction industry in the network.

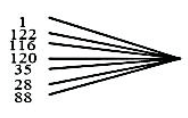

2001

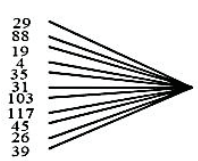

2006

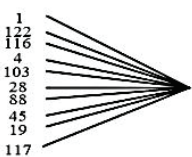

2011

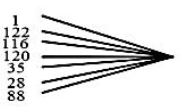

2002

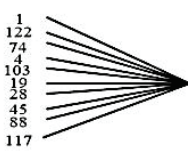

2007

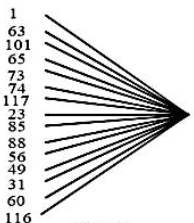

2012

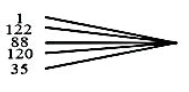

2003

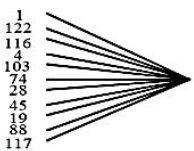

2008

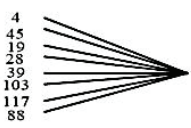

2013

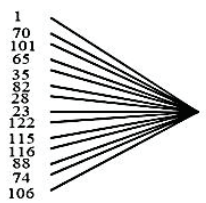

2004

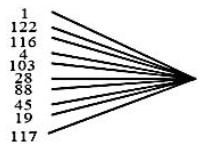

2009

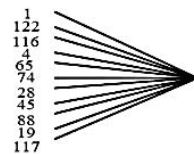

2014

Figure 7 Division of subgroups of China's construction industry during 2001-2015

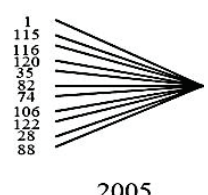

2005

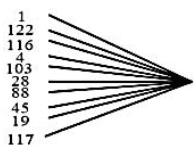

2010

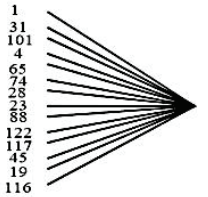

2015

\subsubsection{Cohesive Subgroup Analysis}

The 123 industries were divided into 8 subgroups by Ucinet based on the total consumption coefficients matrix. The division of subgroups of the construction industry was performed during 2001-2015, as shown in Fig. 7.

Construction industry is generally in the same subgroup with crop cultivation, public administration, educational services, wearing apparel, other food products, livestock, its products, eating and drinking places, health services, and medical and pharmaceutical products, thereby indicating the close relationships between the construction industry and these industries. However, the industries in the same subgroup with the construction industry varied in different years. Some industries exit or enter the subgroup of the construction industry in each year. According to the cohesive subgroup analysis, although the role of the construction industry in the industrial network declines, it still maintains a close relationship with many traditional industries. As a traditional industry, the construction industry can easily form symbiotic relationships with other traditional industries. Moreover, members of the construction industry subgroup change dynamically, indicating the unstable symbiotic 
relationships between construction industry and other industries. Forming robust and extensive associations between the construction industry and other industries is a great challenge to China's construction industry.

\section{CONCLUSION}

To determine the direct and indirect associations between China's construction industry and other industries clearly, the evolution of the construction industry was analyzed from its interactions with other industries. In this study, the total consumption coefficients, total distribution coefficients, pull coefficients, and push coefficients of China's construction industry during 2001-2015 were calculated based on the EORA input-output table. On this basis, complex network topologies of industries in China were constructed. The evolutionary trend of China's construction industry in association with other industries in 15 years was determined through input-output analysis, centrality analysis and cohesive subgroup analysis. Some major conclusions could be drawn, as follows:

(1) The construction industry has a significant pull effect on industries whose products are major production elements (e.g., petroleum refining, coal mining and processing, gas production and supply, steel processing, electricity and steam production, and crude oil products). The construction industry has a significant push effect on industries related to people's livelihood (e.g., educational services, real estate, public administration, wholesale and retail trade, resident services, and health services). No substantial changes are observed in the consumption and distribution structures of the construction industry to other industries in 15 years. Influenced by the reform and transition, the pull and push effects of the construction industry on other industries are weakened significantly and failed to change throughout the years.

(2) The push effect of other industries on the construction industry is stronger than the push effect of the construction industry on other industries. The pull effect of other industries on the construction industry began to exceed the pull effect of the construction industry on other industries after 2006. This gap increased significantly in 2013, thereby indicating that the construction industry can transform from a pillar industry to an industry driven by other industries.

(3) The control of the construction industry in the network began to weaken significantly after 2006, as manifested by the further weakening of its hub position in the network. Although the construction industry forms symbiotic relationships with other traditional industries, no robust and extensive associations between them have been established. With the gradual perfection of urbanization in China, the symbiotic relationship between the construction industry and other traditional industries faces complex issues.

The evolution of China's construction industry has been analyzed based on the input-output method and complex network analysis. This analysis not only considers the complex associations between different industries and dynamic changes of industries but also concludes the evolutionary trend of the construction industry in association with other industries in middle and long periods. Study results further prove that China's construction industry is in a key moment of transition and updating. In the future, the construction industry shall improve the construction efficiency, strengthen its pull and push effect on other industries and its association with emerging industries, and construct a more robust and extensive industrial network.

This study offsets the poor coverage of industrial sectors in existing studies on the evolution of construction industry and lays a theoretical foundation for the government to formulate an industrial development plan and reform policies of the construction industry. Data in this study are collected from EORA database, which is updated slowly. Further studies shall strengthen timeliness of network analysis of the construction industry and predict the further development trend of the construction industry.

\section{Acknowledgements}

This study was supported by the China Postdoctoral Science Foundation (No. 2018M633321), National Natural Science Foundation of China (No. 71801024), Fundamental Research Funds for Central Universities (No. 2018CDXYJG0047), Youth Project of science and technology research program of Chongqing Education Commission of China (No. KJQN201800125), and the City Science of Chongqing (Integration and demonstration of key technology research of prefabricated housing construction, 2015 No. 0-1).

\section{REFERENCES}

[1] Huo, T. F., Ren, H., Cai, W. G., Feng, W., Tang, M. H., \& Zhou, N. (2018). The total-factor energy productivity growth of China's construction industry: evidence from the regional level. Natural Hazards, 92(3), 1593-1616. https://doi.org/10.1007/s11069-018-3269-0

[2] Liao, Y. (2017). Transformation pathway of Chinese construction enterprises. BoletinTecnico, 55(8), 350-356.

[3] Zhang, X. L., Skitmore, M., \& Peng, Y. (2014). Exploring the challenges to industrialized residential building in China. Habitat International, 41, 176-184. https://doi.org/10.1016/j.habitatint.2013.08.005

[4] Hong, J. K., Shen, Q. P., \& Xue, F. (2016). A multi-regional structural path analysis of the energy supply chain in China's construction industry. Energy Policy, 92, 56-68. https://doi.org/10.1016/j.enpol.2016.01.017

[5] Ngowi, A. B., Pienaar, E., Talukhaba, A., \& Mbachu, J. (2005). The globalisation of the construction industry- a review. Building and Environment, 40(1), 135-141. https://doi.org/10.1016/j.buildenv.2004.05.008

[6] Hasan, A., Baroudi, B., Elmualim, A., \& Rameezdeen, R. (2018). Factors affecting construction productivity: a 30 year systematic review. Engineering, Construction and Architectural Management, 25(7), 916-937. https://doi.org/10.1108/ECAM-02-2017-0035

[7] Ofori, G. \& Han, S. S. (20 03). Testing hypotheses on construction and development using data on China's provinces, 1990-2000. Habitat International, 27(1), 37-62. https://doi.org/10.1016/S0197-3975(02)00034-6

[8] Yung, P. \& Yip, B. (2010). Construction quality in China during transition: A review of literature and empirical examination. International Journal of Project Management, 28(1), 79-91. https://doi.org/10.1016/j.jproman.2009.03.003 
[9] Crosthwaite, D. (2000). The global construction market: a cross-sectional analysis. Construction Management \& Economics, 18(5), 619-627. https://doi.org/10.1080/014461900407428

[10] Choi, D. S., Le, H., \& Lee, Y. D. (2013). The relationship between Korean construction industry and GDP in economic development process. Korean Journal of Construction Engineering and Management, 14(6), 70-77. https://doi.org/10.6106/KJCEM.2013.14.6.070

[11] Ick, B. J. (2016). A comparative input-output analysis of the construction industry in Korea and EU countries. Korean Journal of EU Studies, 21(2), 53-81.

[12] Liu, C. L. \& He, S. M. (2016). Input-output structures of the Australian construction industry. Construction Economics and Building, 16(2), 56-70. https://doi.org/10.5130/AJCEB.v16i2.4819

[13] Chen, Y., Liu, B. S., Shen, Y. H., \& Wang, X. Q. (2018). Spatial analysis of change trend and influencing factors of total factor productivity in China's regional construction industry. Applied Economics, 50(25), 2824-2843. https://doi.org/10.1080/00036846.2017.1409421

[14] Mao, C., Shen, Q. P., Pan, W., \& Ye, K. H. (2015). Major barriers to off-site construction: the developer's perspective in China. Journal of Management in Engineering, 31(3), 18. https://doi.org/10.1061/(ASCE)ME.1943-5479.0000246

[15] Arditi, D., Kale, S., \& Tangkar, M. (1997). Innovation in construction equipment and its flow into the construction industry. Journal of Construction Engineering \& Management, 123(4), 371-378. https://doi.org/10.1061/(ASCE)0733-9364(1997)123:4(371)

[16] Ofori, G. (2003). Preparing Singapore's construction industry for the knowledge-based economy: practices, procedures and performance. Construction Management \& Economics, 21(2), 113-125. https://doi.org/10.1080/0144619032000079680

[17] Kim, H. J. \& Reinschmidt, K. F. (2012). Market structure and organizational performance of construction organizations. Journal of Management in Engineering, 28(2), 212-220. https://doi.org/10.1061/(ASCE)ME.1943-5479.0000082

[18] Zeng, S. X., Chen, H. M., \& Tam, C. M. (2005). Market structure of the construction industry of China. Architectural Science Review, 48(4), 367-375. https://doi.org/10.3763/asre.2005.4844

[19] Liu, Y. S., Zhao, X. F., \& Liao, Y. P. (2013). Market structure, ownership structure, and performance of China's construction industry. Journal of Construction Engineering \& Management, 139(7), 852-857. https://doi.org/10.1061/(ASCE)C0.1943-7862.0000656

[20] Li, X. D., Shen, C., Wu, Z., \& Yang, J. M. (2013). Comparison of the efficiency of construction industry among four districts: Beijing, Shanghai, Zhejiang and Jiangsu. Journal of Engineering Management, 27(1), 1-4.

[21] Liu, B. S., Chen, Y., Wang, R., Shen, Y. H., \& Shen, Q. P. (2016). Different interaction mechanisms of market structure in the construction industry TFP from the spatial perspective: A case study in China. KSCE Journal of Civil Engineering, 20(1), 23-33. https://doi.org/10.1007/s12205-015-0444-7

[22] Chen, P. C., Alvarado, V., \& Hsu, S. C. (2018). Water energy nexus in city and hinterlands: Multi-regional physical inputoutput analysis for Hong Kong and South China. Applied Energy, 225, 986-997. https://doi.org/10.1016/j.apenergy.2018.05.083

[23] Lenzen, M., Kanemoto, K., Moran, D., \& Geschke, A. (2012). Mapping the structure of the world economy. Environmental Science \& Technology, 46(15), 8374-8381. https://doi.org/10.1021/es300171x

[24] Luo, J. X. (2013). The power-of-pull of economic sectors: A complex network analysis. Complexity, 18(5), 37-47. https://doi.org/10.1002/cplx.21444

[25] Diaz, B. \& Morillas, A. (2011). Incorporating uncertainty in the coefficients and multipliers of an IO table: A case study. Papers in Regional Science, 90(4), 845-861. https://doi.org/10.1111/j.1435-5957.2010.00341.x

[26] Rendon, D. L. T. S, Kalda, J., Kitt, R., \& Engelbrecht, J. (2016). On the topologic structure of economic complex networks: Empirical evidence from large scale payment network of Estonia. Chaos, Solitons \& Fractals, 90, 18-27. https://doi.org/10.1016/j.chaos.2016.01.018

[27] Li, B., Xiang, P. C., Hu, M. M., Zhang, C. B., \& Dong, L. (2017). The vulnerability of industrial symbiosis: a case study of Qijiang Industrial Park, China. Journal of Cleaner Production, 157, 267-277. https://doi.org/10.1016/j.jclepro.2017.04.087

[28] Ding, C. F. \& Li, K. (2018). Centrality ranking in multiplex networks using topologically biased random walks. Neurocomputing, 312, 263-275. https://doi.org/10.1016/j.neucom.2018.05.109

[29] Kumar, P., Gupta, S., \& Bhasker, B. (2017). An upper approximation based community detection algorithm for complex networks. Decision Support Systems, 96, 103-118. https://doi.org/10.1016/j.dss.2017.02.010

[30] Lenzen, M., Moran, D., Kanemoto, K., \& Geschke, A. (2013). Building eora: A global multi-region input-output database at high country and sector resolution. Economic Systems Research, 25(1), 20-49. https://doi.org/10.1080/09535314.2013.769938

\section{Contact information:}

\section{Xianrui MA}

School of Construction Management and Real Estate, Chongqing University No. 174 Shazhengjie, Shapingba District, Chongqing, 400045 China E-mail: thomasmahd@sina.com

\section{Chunlei HUANG}

Chongqing JianZhu College,

857 Lihua Avenue, Nanan District, Chongqing, 400072 China

E-mail:273686535@qq.com

Yan FU, corresponding author

1) School of Construction Management and Real Estate, Chongqing University, 2) Chongqing University Center for Construction Economics and Management, Chongqing University,

No. 174 Shazhengjie, Shapingba District, Chongqing, 400045 China

E-mail:64472221@qq.com

\section{Jingxin GAO}

School of Construction Management and Real Estate, Chongqing University, No. 174 Shazhengjie, Shapingba District, Chongqing, 400045 China E-mail:2524292135@qq.com

\section{Beibei QIN}

School of Built Environment, University of Reading, Old Whiteknights Campus, Reading, UK, RG6 6AW

E-mail: b.qin@pgr.reading.ac.uk 